\title{
External root resorption: diagnosis and treatment. clinical case report
}

\begin{abstract}
Root resorptions are pathologies usually diagnosed by X-Ray rotine evaluation. They can be classified as internal, when root canal is involved and external, when periodontal ligament is involved. External root resorptions are processes in which the loss of cementoblasts occurs causing the mineralized surfaces to be susceptible to the action of clastic cells. The treatment of root resorption is basically root and / or periodontal endodontic treatment, depending on the location and extent of the reabsorption. When it attacks the cervical region, radical endodontic treatment can usually be associated with surgical complementation. The present study aims to analyze the efficacy obtained with the treatment of external cervical radicular resorption of an individual attended at the Hospital for Rehabilitation of Craniofacial Anomalies (HRAC / USP), in which periodontal treatment and clinical and radiographic followup were performed. This study presents a more conservative alternative treatment of external root resorption, with preservation of the pulp vitality of the dental element accompanied by the apparent stabilization of the resorptive process without the need for radical endodontic treatment.
\end{abstract}

Keywords: External root resorption, Endodontics, Periodontics, Dental pulp
Volume 9 Issue 2 - 2018

\author{
Jayne Barbosa dos Santos,' José Francisco \\ Mateo-Castillo, ${ }^{2}$ Celso Kenji Nishiyama, ${ }^{3}$ Luis \\ Augusto Esper, ${ }^{4}$ Lidiane de Castro Pinto, ${ }^{5}$ \\ Claudia Ramos Pinheiro 6 \\ 'Resident of Endodontic Postgraduate, Dentist Surgeon, \\ Hospital for Rehabilitation of Craniofacial Anomalies, Brazil \\ ${ }^{2}$ Specialist in Endodontics, Masters in Rehabilitation Sciences, \\ $\mathrm{PhD}$ Student in Rehabilitation Sciences, Hospital for \\ Rehabilitation of Craniofacial Anomalies, Brazil \\ ${ }^{3}$ Scientific Coordinator of CPO Uninga, Bauru, São Paulo, Brazil, \\ $\mathrm{PhD}$ in Endodontics, Brazil \\ ${ }^{4}$ Specialist in Periodontics of the Hospital for Rehabilitation of \\ Craniofacial Anomalies, PhD in Oral \\ Rehabilitation, Professor of Periodontics at the Sacred Heart \\ University (USC), Brazil \\ ${ }^{5} \mathrm{PhD}$ in Rehabilitation Sciences, Endodontist and Professor of \\ the Hospital for Rehabilitation of Craniofacial Anomalies, Brazil \\ ${ }^{6}$ Pedagogical Coordinator of the Specialization Course in \\ Endodontics, CPO Uningá, Brazil, PhD in Applied Dental \\ Sciences with emphasis in Microbiology and Immunology, Brazil
}

Correspondence: Lidiane de Castro Pinto, Endodontist and Professor of the Hospital for Rehabilitation of Craniofacial Anomalies, Rua Silvio Marchione 3-20,Vila Universitária, Zip code: I70 I 2900, Bauru, São Paulo, Brazil, Tel +55 |432358080, Email lidianep@usp.br

Received: November 28, 2017 | Published: April 03, 2018

\section{Abbreviations: MTA, Mineral Trioxide Aggregate; pH, Potential of Hydrogen \\ Introduction}

External inflammatory root resorption is a process that starts from minor lesions of the periodontal ligament and/or cementum, due to trauma or contamination with bacteria that induce small root resorption cavities, reaching the dentinal tubules and the root canal. Initially, it does not involve pulp tissue. ${ }^{2}$ It can also be caused by a sudden injury (trauma following reimplantation) or persistence over time (orthodontic force). ${ }^{3}$ The treatment varies according to the severity of the root resorption and in relation to the involvement with the root pulp, ${ }^{4}$ being basically endodontic, however, it depends on the location and extent of reabsorption. In the cervical región, endodontic treatment is usually associated with surgical complementation. ${ }^{5}$ In all cases, there is a need for clinical and radiographic monitoring to assess the success of the proposed therapy. ${ }^{6}$ In addition, the treatment of external resorption that affects the cervical third of the root can be only periodontal. ${ }^{7}$ However, it may present the disadvantage of being more time consuming for the patient and representing risks of aesthetic compromise when the area to be treated is in the anterior región, "considered as an aesthetic facial area". In most cases of external resorption in an extensive or difficult access area, the treatment implemented is surgical; a flap of total thickness being exposed, exposing the defect, and then removing all inflamed tissue and cleaning the area, followed by a restoration of the resorption with materials such as glass ionomer, composite resin, amalgam or Mineral Trioxide Aggregate (MTA). ${ }^{7,8}$ MTA has been shown to provide bioinductive effects, helping with periodontal healing and allowing new cement growth on its surface. ${ }^{4}$ The use of intracanal medication containing calcium hydroxide in its composition increases the chances of scarring. ${ }^{9}$ In addition to maintaining high $\mathrm{pH}$, it has antimicrobial activity and inhibitory action of inflammatory root resorption. ${ }^{10}$ External cervical resorption cases may be asymptomatic because the pulp tissue remains protected due to the surrounding dentin and pre-dentin layer. However, with the evolution of the lesion, communication with the root canal may occur and symptoms associated with irreversible pulpitis arise. ${ }^{11}$ When the lesion is clinically visible, it presents with a pinkish coloration in the cervical portion of the tooth, due to the presence of granulation tissue, which is highly vascularized. ${ }^{11}$ In the differential diagnosis of external cervical resorption, these cases usually respond positively to the thermal sensitivity test. ${ }^{12}$ Regarding the treatment of cervical inflammatory resorptions, the exposure of the lesion, removal of granulomatous tissue and restoration of the resorbed area is recommended..$^{13}$ Endodontic treatment as a function of the amount of dentin that separates the floor of the pulp chamber from the area reabsorbed by the root canal may or may not be necessary. ${ }^{13}$ 
In the treatment of external cervical resorption there is no biological need to remove the pulp and perform the endodontic treatment; this is only justifiable in cases where the reabsorption may be very deep and extensive, being very close to the pulp and difficult to protect. ${ }^{14}$ Endodontic treatment is often necessary in advanced reabsorption situations, with contamination of the pulp chamber or root canal. In these cases, endodontic treatment is essential, not only because of the extent of external cervical resorption, but also because of the risk of intracanal bacterial contamination through reabsorption. ${ }^{15}$ In other cases resorption may occur only with surgical treatment, with removal of granulation tissue followed by restoration of the root defect and periodontal intervention. ${ }^{16}$ The Clark radiographic technique is a method of radiographic localization consisting of two periapical radiographic shots with variation of the angle of incidence of the radius (mesial and distal), and in fact this variation is provided in the radiographic image. The internal deformity accompanies the image in all angulations and the external resorption is removed from the canal when the angulation of incidence is modified. This difference exists because the defect of the internal resorption is the result of the deformation of the dentin walls in a space that will be occupied by the root canal, while the external resorption is separated and is frequently superficial in relation to the root surface lateral to the canal. In addition, these radiographs may reveal the side of the affected root in cases of external resorption. ${ }^{17}$ There were no reports of recurrence of external cervical resorption in teeth with pulp vitality, with the prognosis being favorable in such cases. ${ }^{14}$ Regarding external tooth resorption by substitution, the prognosis is unfavorable and will inevitably lead to loss of the affected tooth. ${ }^{14}$ When treatment of resorptions is periodontal, curettage of reabsorbed tissue is indicated, followed by placement of calcium hydroxide or MTA to neutralize the microbial byproducts that may be affecting the area, mainly to induce neoformation and scarring. ${ }^{18}$ Thus, this study aims to present a clinical case report in which the treatment of an external cervical resorption was carried out, only with the execution of the periodontal treatment, through which it was possible to maintain pulp vitality and rehabilitation of the dental element.

\section{Case presentation}

A 43-year-old individual of the female gender, where in the periapical orthodontic radiographic evaluation of the left upper canine tooth (23), a radiolucency zone was observed in the cervical region (Figure 1) and clinically an area of gingival deformity and enamel wear close to the amelocementary union of the crown of the dental element (Figure 2); responding negatively to the percussion test and positive response to the cold stimulus of the thermal sensitivity test, indicating pulp vitality. Based on these results, the external resorption was diagnosed, since the root canal was not compromised by the lesion, the image of the canal being different from the image of the edge of the reabsorbed cavity. The exact location of the resorption was determined by the periodontal catheter, being located in the cervical region (Figure 3A). Periodontal surgery was performed, performing a total flap for the removal of granulation tissue and indirect pulp protection with MTA (Angelus, Londrina, PR, Brazil) (Figure 3B). The cavity was sutured with Vicryl type suture (ETHICON, São Paulo, SP, Brazil) (Figure 3C) with posterior surgical cement placement (COE PAK, Alsip, Illinois, USA). It is important to say that before the suture, the provisional restoration was performed with glass ionomer cement (FGM, Joinvile, SC, Brazil) (Figure 3D). As postsurgical indications, analgesic and rinses with chlorhexinide gluconate (Neo Química, Anápolis, GO, Brazil) were prescribed. After the first month, a clinical and radiographic evaluation of the control was performed. The tissues with normal appearance (apparent stability of the resorbed process), well sealed area with temporary restorative material and absence of symptomatology in the dental piece were observed (Figure 4). The final restoration of the cervical vestibular area of tooth 23 was performed with dentin-A3 composite resin and A3 enamel (3M do Brasil Ltda, Sumaré, SP, Brazil) (Figure 5). The patient returned for clinical and radiographic control after 1 year of treatment completion. Clinically, preservation of the function and aesthetics of the composite resin restoration could be observed (Figure 6). The radiographic image indicates apparent stability of reabsorption (Figure 7).



Figure I Diagnostic X-ray.

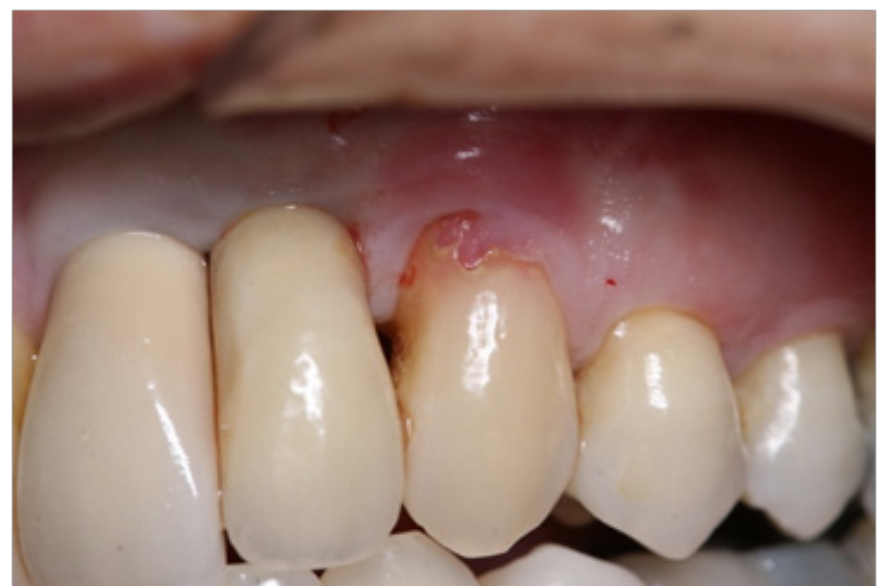

Figure 2 Initial clinical picture of the resorption area of the upper left canine tooth (23). 


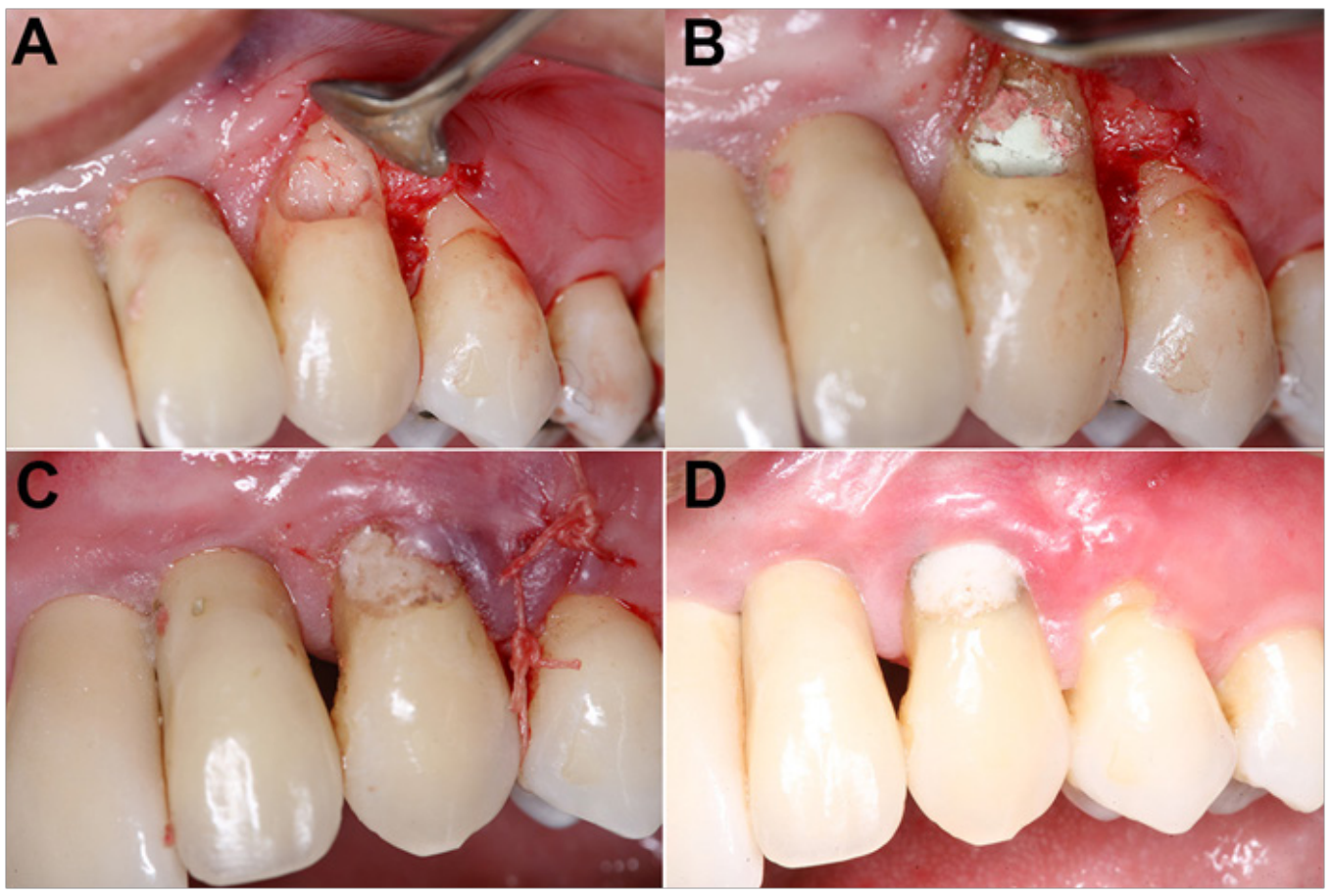

Figure $3 \mathrm{It}$ shows the sealing process of the cavity formed by the reabsorption of the tooth 23 .

(A) Exposure of the area of resorption;

(B) Sealing with MTA of the reabsorbed area;

(C) Suturing of the surgical area;

(D) Temporary restoration with Glass lonomer Cement.

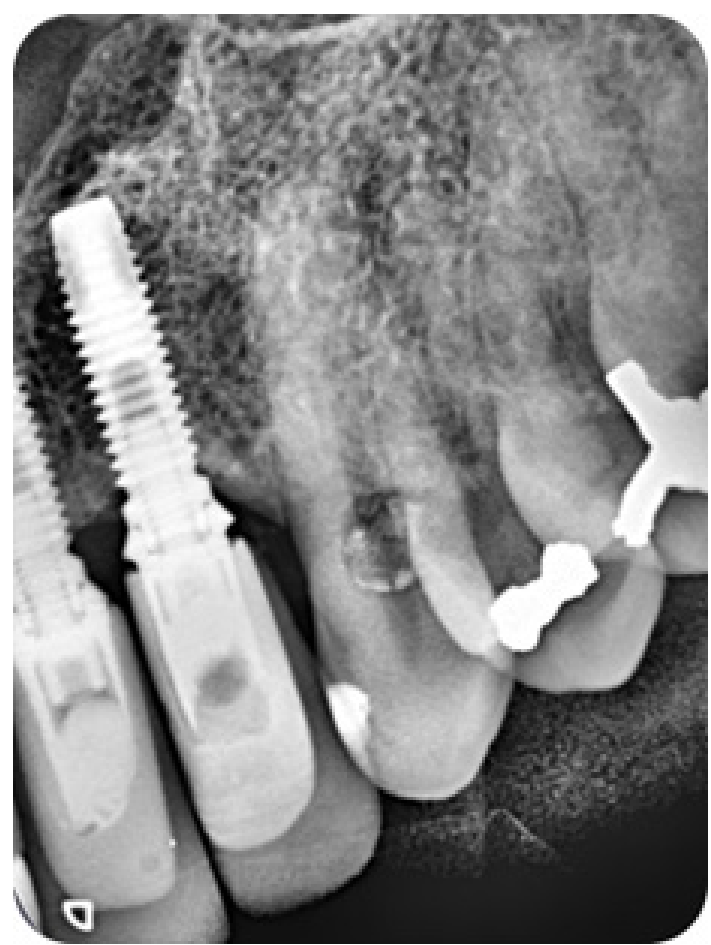

Figure $4 \mathrm{X}$-ray control of the first month.

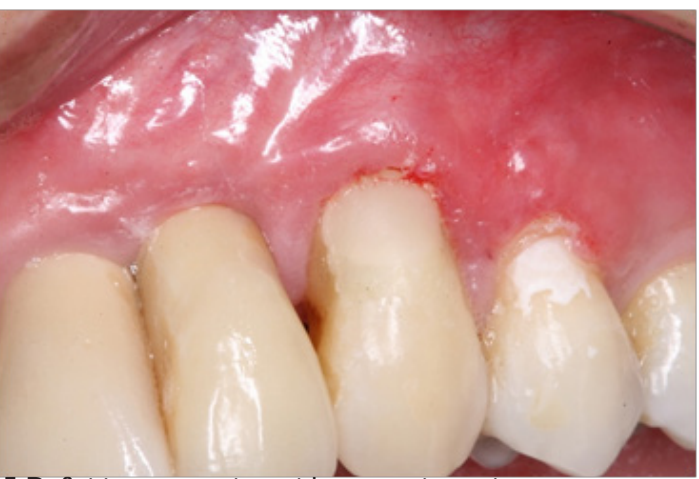

Figure 5 Definitive restoration with composite resin.

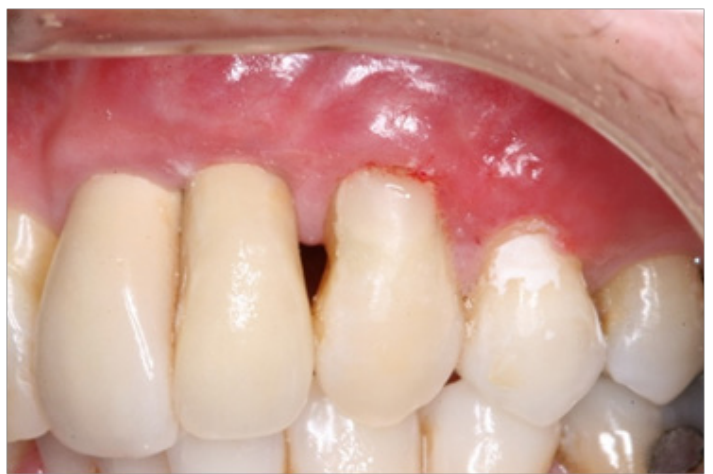

Figure 6 Clinical appearance after I year. 


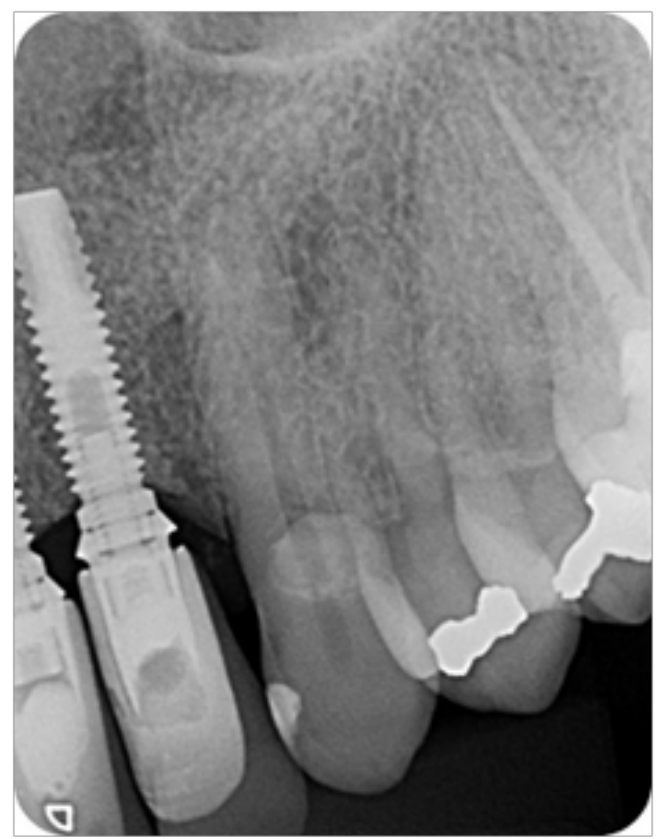

Figure 7 Control X-ray ( $\left.\right|^{\text {st }}$ year $)$

\section{Discussion}

Root Resorptions diagnosis is one of the key points to determine the therapy plan. Problem detection at the beginning of this development, the exact removal of resorption tissue, endodontic treatment when indicated and restauration of the defects caused by resorption with an adequate isolation of operating field. ${ }^{19}$ The treatment of external cervical resorption consists of the removal of all granulation tissue present in the reabsorbed region and in the filling of this region with a material that does not allow the penetration of clastic cells so that it does not injure the periodontal tissue. Typically, in this type of reabsorption, there is no communication of the reabsorbed area with the root canal, so endodontic treatment is not necessary in all cases. However, in clinical practice, when reabsorption is very close to the pre-dentin, exposure of the pulp may occur during curettage. In cases of very extensive resorption, endodontic treatment may be chosen prior to the end of treatment for resorption. ${ }^{20}$ Radical endodontic therapy should be performed in cases of diagnosis of pulpal necrosis or when there is a need for restoration of the reabsorbed area and access needs to be performed via the root canal. ${ }^{21}$ In contrast, periodontal surgery and restoration of resorption defects following the healing of periodontal tissues is also a recommended treatment behavior for preserving pulp vitality. ${ }^{18,19}$ In severe external resorptions, in which the pre-dentin layer remains protecting the pulp; it has been suggested that the organic phase of pre-dentin contains an inhibitory enzyme against reabsorption..$^{18}$ Periapical radiography is the main method of distinguishing external / internal resorption; however, in many cases it is not sufficient for a correct diagnosis or to define the actual extent of the lesion. ${ }^{22}$ The use of cone beam computed tomography can be an important means of diagnosis in these cases. This imaging technique can confirm the actual extent of reabsorption and the possibility of communication with the periodontal space. ${ }^{23,24}$ Despite the fact that some types of dental resorption (Clark and Cone Beam techniques are necessary for a correct diagnosis), in the case reported, just the radiographic periapical was sufficient to determine the diagnosis. The
Clark technique is an auxiliary strategy in the differential diagnosis between external and internal resorption; if the resorption is internal, the radiographic relationship between the root canal and the resorption cavity is not altered even if the horizontal angulation is modified, as opposed to external resorption, in which modification can be observed..$^{25}$ Initially in the treatment of external cervical resorption, it is possible to use glass ionomer cement as a sealant. After six months of treatment, if in the control evaluation, the asymptomatic patient is observed; as well as in the present case, we proceeded to surgical exposure and curettage of the lesion, and the cavity was sealed with glass ionomer and the restoration was performed with composite resin. ${ }^{25}$ Mineral Trioxide Aggregate (MTA) has been considered a promising material in root canal treatment of root resorption. An important biological property is the stimulation of new bone formation, and due to its alkaline $\mathrm{pH}$ and biocompatibility, does not trigger severe inflammation at the local regeneration. ${ }^{26,27}$ This material seems to be advantageous for the repair of perforations and resorption, since it allows the deposition of cement, providing a very effective biological seal, this is mainly due to its ability to set itself up in the presence of moisture. ${ }^{26}$ For these and other characteristics, MTA has several potential clinical applications to possess dimensional stability in the presence of blood and microbial byproducts; besides being biocompatible and radiopaque. ${ }^{28}$ In this study, the material chosen for the sealing of the reabsorbed area was MTA, which, according to its properties, allows a sealed sealing of the restored area and stabilizes the reabsorption process. Root reabsorption is an asymptomatic clinical condition diagnosed by radiographic examinations..$^{22}$ In cases of invasive cervical resorption, an option of treatment consists of orthodontic traction allowing the exposure of the edges of the lesion and correct prosthetic treatment of the dental element from the creation of a total crown. ${ }^{29,30}$ In the present case, a restoration with a composite resin was performed, since failure to restore immediately could lead to compromising the seal quality of the area with the MTA, resulting in failure due to leaks that may lead to a new infectious process. ${ }^{31}$ Based the above, the clinical and radiographic examination is unpredictable for the correct diagnosis in cases of external root resorption, which can enable effective treatment and achieve satisfactory results; (as in the present case) the pulp vitality of the affected dental element can be preserved, thus guaranteeing an apparent stability of the resorption process without the need for radical endodontic treatment.

\section{Acknowledgment}

Jayne Barbosa dos Santos (Performed the last annual clinical controls of the case, elaboration, description and presentation of the clinical case for the manuscript) José Francisco Mateo-Castillo (Collaborated in the elaboration of the case and responsible for the part x-ray and clinical photographs and methodological part of the manuscript), Celso Kenji Nishiyama (Contributing to the description and detailed correction of the manuscript) Luis Augusto Esper, (He performed part of the periodontal treatment and collaborated in the preparation of the manuscript) Lidiane de Castro Pinto (Responsible for the evaluation and control of multidisciplinary treatment) Claudia Ramos Pinheiro performed the correction, elaboration, description and presentation of the clinical case).

\section{Conflict of interest}

Author Jayne Barbosa dos Santos declares no conflict of interest. Author José Francisco Mateo-Castillo declares no conflict of interest. Author Celso Kenji Nishiyama declares no conflict of interest. Author 
Luis Augusto Esper declares no conflict of interest. Author Lidiane de Castro Pinto declares no conflict of interest. Author Claudia Ramos Pinheiro declares no conflict of interest.

\section{References}

1. Consolaro A. The four mechanisms of dental resorption initiation. Dental Press J Orthod. 2013;18(3):7-9.

2. Mavridou AM, Pyka G, Kerckhofs G, et al. A novel multimodular methodology to investigate external cervical tooth resorption. Int Endod J. 2016;49(3):287-300.

3. William Barnabé, João Batista de Souza, Lawrence Gonzaga Lopes, et al. Abordagem Interdisciplinar no Tratamento de Reabsorção Cervical Externa: Relato de Caso. Revista Odontológica do Brasil Central. 2011;20(55):359-365.

4. Kusgoz A, Yildirim T, Alp CK, Tanriver M. Management of root resorption with mineral trioxide aggregate complicated by a luxation injury: report of a case with six-year follow-up. J Pak Med Assoc. 2017;67(1):134-136.

5. Camargo SEA, Moraes MEL, Moraes LC, et al. Principais características clínicas e radiográficas das reabsorções radiculares internas e externas. Revista de Odontologia da Universidade Cidade de São Paulo. 2008;20(2):195-203.

6. Roig M, Morelló S, Mercadé M, et al. Invasive cervical resorption: report on two cases. Oral Surg Oral Med Oral Pathol Oral Radiol Endod. 2010;110(4):64-69.

7. Yilmaz Hg, Kalender A, Cengiz E. Use of mineral trioxide aggregate in the treatment of invasive cervical resorption: a case report. $J$ Endod. 2010;36(1):160-163.

8. Ikhar A. Management of external invasive cervical resorption tooth with mineral trioxide aggregate: A case report. Case Rep Med. 2013:139801

9. Barbin EL, Saquy PC, Guedes DFC, et al. Determination of para-chloroaniline and reactive oxygen species in chlorhexidine and chlorhexidine associated with calcium hydroxide. $J$ Endod. 2008;34(12):1508-1514.

10. Umer F, Adnan S, Raza Khan F. Conservative management of invasive cervical resorption: a case report. J Dent (Tehran). 2013;10(3):289-295.

11. Heithersay GS. Invasive cervical resorption: an analysis of potential predisposing factors. Quintessence Int. 1999;30(2):83-95.

12. Patel S, Kanagasingam S, Pitt Ford T. External cervical resorption: a review. J Endod. 2009;35(5):616-625.

13. Lopes HP, Siqueira Junior JF, Elias CN. Endodontia: Biologia e técnica. $2^{\text {nd }}$ ed, Guanabara Koogan Rio de Janeiro: Brazil;2004:419-480.

14. Consolaro A, Bittencourt G. Why not to treat the tooth canal to solve external root resorptions? Here are the principles. Dental Press J Orthod. 2016;21(6):20-25.

15. Estevez R, Aranguren J, Escorial A, et al. Invasive cervical resorption class III in a maxillary central incisor: diagnosis and follow-up by means of cone-beam computed tomography. J Endod. 2010;36(12):2012-2014.
16. Macalossi JMS, Back EDEE, Haragushiku GA, et al. Etiology, diagnosis and treatment of external cervical resorption - literature review. Odonto. 2012;20(39):71-80.

17. Silva EJNL, Carvalho NK, Carvalho FR, et al. Abordagem Endodôntica e Visão Ortodôntica da Reabsorção Cervical Externa: Relato de Caso. Rev Odontol Bras Central. 2011; 20(52):94-98.

18. Bergmans L, Van Cleynenbreugel J, Verbeken E, et al. Cervical external root resorption in vital teeth. J Clin Periodontol. 2002;29(6):580-585.

19. Venuti L. Operating protocols of external root cervical resorption. Giornale Italiano di Endodonzia. 2015;29(1):9-29.

20. Trope M. Root resorption due to dental trauma. JEndod. 2002;1(1):79-100.

21. Heward S, Sedgley CM. Effects of Intracanal Mineral Trioxide Aggregate and Calcium Hydroxide During Four Weeks on $\mathrm{pH}$ Changes in Simulated Root Surface Resorption Defects: An In Vitro Study Using Matched Pairs of Human Teeth. J Endod. 2011;37(1):40-44.

22. Vasconcelos, KF, Nejaim Y, Haiter Neto F, et al. Diagnosis of invasive cervical resorption by using cone beam computed tomography: Report of two cases. Braz Dental J. 2012;23(5):602-607.

23. Baranwal AK. Management of external invasive cervical resorption of tooth with Biodentine: A case report. J Conserv Dent. 2012;19(3):296299.

24. Lima TF, Gamba TO, Zaia AA, Soares AJ. Evaluation of cone beam computed tomography and periapical radiography in the diagnosis of root resorption. Aust Dent J. 2016;61(4):425-431.

25. Hiremath H, Yakub SS, Metgud S, et al. Invasive cervical resorption: a case report. J Endod. 2007;33(8):999-1003.

26. Tessare P, Fonseca, B, Britto, M. Propriedades, características e aplicações clínicas do agregado trióxido mineral - mta. Uma nova perspectiva em endodontia. Revisão de literatura. Electronic J Endodontics Rosario. 2005;1(4):1-15.

27. Kqiku L, Ebeleseder K A, Glockner K. Treatment of invasive cervical resorption with sandwich technique using mineral trioxide aggregate: a case report. Oper Dent. 2012;37(1):98-106.

28. Maja BS, Ryta $\measuredangle$, Matylda T, et al. Perforating internal rootresorption repaired with mineral trioxide aggregate caused complete resolution of odontogenicsinus mucositis: a case report. J Endod. 2015;41(2):274-278.

29. Smidt A, Nuni E, Keinan D. Invasive Cervical Root Resorption: Treatment Rationale with an Interdisciplinary Approach. $J$ Endod. 2007;33(11):1383-1387.

30. Consolaro A. Tracionamento ortodôntico: possíveis consequências nos caninos superiores e dentes adjacentes. Parte 1: reabsorção cervical externa nos caninos tracionados. Dent Press J Orthod. 2010;15(4); 23-30.

31. Luckmann G, Dorneles, LC, Grando CPC. Etiologia dos insucessos dos tratamentos endodônticos. Vivências: Revista Eletrônica de Extensão da URI. 2013;9(16):133-139. 